\title{
As contribuições dos objetos de aprendizagem para o ensino de números racionais no Ensino Fundamental
}

\author{
The contributions of the learning objects for the teaching of rational numbers in \\ Fundamental Education
}

Tahieny Kelly de Carvalho Instituto Federal de Educação Ciência e Tecnologia do Sudeste de Minas Gerais (IF Sudeste MG) Campus Rio Pomba, Rio Pomba, MG, Brasil tahieny174@hotmail.com

Geraldo Francisco Côrrea Alves de Lima Instituto Federal de Educação Ciência e Tecnologia do Sudeste de Minas Gerais (IF Sudeste MG) Campus Rio Pomba, Rio Pomba, MG, Brasil geraldo.lima@ifsudestemg.edu.br

Fernando Alves Martins Instituto Federal de Educação Ciência e Tecnologia do Sudeste de Minas Gerais (IF Sudeste MG) Campus Rio Pomba, Rio Pomba, MG, Brasil fernando.alves@ifsudestemg.edu.br

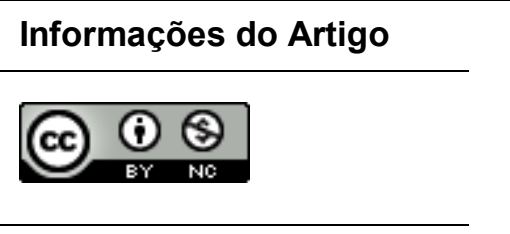

Histórico do Artigo

Submissão: 05 de março de 2018.

Aceite: 08 de junho de 2018.

\section{Palavras-chave}

Ensino de Matemática

Objetos de Aprendizagem

Tecnologia da Informação e

Comunicação

\section{Resumo}

Com o avanço das tecnologias, a sociedade vem passando por diversas transformações e, com isso, causando mudanças também na educação. Nessa situação, com o crescimento das TIC's (Tecnologias da Informação e Comunicação), os objetos de aprendizagem estão se tornando importantes instrumentos complementares na construção do ensino-aprendizagem. Segundo Santos e Moita (2016), as tecnologias podem contribuir para a educação, gerando simulações que possam generalizar e transferir tais conhecimentos a outros contextos, pois um conhecimento só se torna pleno quando pode ser aplicado em situações diferentes daquelas que lhe deram origem. Refletindo sobre a prática existente nas escolas, e a grande dificuldade dos alunos em compreender os conceitos de números racionais, surgiu o interesse em desenvolver um material com o objetivo de tornar esse conteúdo mais atrativo, por meio de atividades que favoreçam o desenvolvimento do pensamento algébrico, ao atribuir significado aos elementos presentes neste pensamento. O objeto de aprendizagem desenvolvido para este trabalho consiste em jogos matemáticos nos quais os alunos possam se sentir empolgados e ao mesmo tempo aprenderem a Matemática de forma lúdica e divertida. O material trouxe contribuições positivas para as aulas, pois fez com que os alunos compreendessem melhor as operações com números racionais e se sentissem mais motivados a realizar as atividades que foram propostas em sala de aula.

\section{Abstract}

With the advancement of technologies, society has been undergoing several transformations and, with that, causing changes also in education. In this situation, with the growth of TIC's, the learning objects are becoming important complementary instruments to the construction of teaching-learning. According to Santos and Moita (2017) technologies can contribute to education, enabling simulations that can generalize and transfer such knowledge to other contexts, since knowledge becomes complete only when it can be applied in different situations of those that gave rise to it. Reflecting on the existing practice in schools, and the great difficulty of students in understanding the concepts of rational numbers, the interest arose in developing a material with the purpose of making this content more attractive, through activities that favor the development of 
algebraic thinking, by assigning meaning to the elements present in this thought. The learning object developed for this work consists of mathematical games in which students can feel excited and at the same time learn mathematics in a playful and fun way. The material brought something positive to the class as it made the students better understand the concepts of rational numbers and felt more motivated to carry out the activities that were proposed in class.

\section{Introdução}

A educação e a sociedade vêm sofrendo mudanças e os professores estão percebendo que, em sala de aula, está cada vez mais difícil encontrar a motivação dos alunos em relação ao estudo, principalmente em relação à Matemática. Diante disso, surgiu o interesse em elaborar objetos de aprendizagem para o ensino de números racionais, e aplicá-los em sala de aula a fim de verificar a mudança de interesse dos alunos pela disciplina de Matemática com intuito de facilitar o processo de ensino e aprendizagem desta disciplina.

Segundo Santos e Moita (2016), as Tecnologias de Informação e Comunicação (TIC's) podem contribuir com o ensino, garantindo simulações em que os alunos possam observar regularidades, generalizar e transferir tais conhecimentos a outros contextos. Na era da tecnologia, o uso de objetos tecnológicos pode estimular a capacidade de concentração do aluno durante as aulas. Para Smole e Diniz (2005), o uso da tecnologia da informação e comunicação na educação é uma ferramenta indispensável ao docente, pois pode aumentar a eficácia do ensino, desenvolvendo o senso crítico e o pensamento hipotético e dedutivo, além de permitir maior interação entre os diversos conhecimentos adquiridos em diferentes contextos. Nesse sentido,

Os meios eletrônicos permitem diferentes formas de interação com o conhecimento através de representações iconográficas, imagéticas, hipertextos e multimídia, representando importantes fontes de informação como os livros, textos, revistas, filmes, etc. Na escola servem não apenas para atualizar os conhecimentos, mas para socializar experiências e aprendizagem permanente." (BRASIL, 1998, p. 140).

Contudo, apesar dos professores estarem inseridos em uma sociedade de alta tecnologia, pode-se observar em alguns ambientes de trabalho, que muitos deles não alteram a prática de ensino por falta de conhecimento básico em informática. Não é necessário apenas que o professor conheça o conteúdo, mas também é necessário contatar com teorias educacionais, perspectivas metodológicas e tecnológicas, principalmente no próprio contexto em que trabalha (PONTE et al., 2003).

Atuando como docente, percebo que muitos alunos possuem certo receio ao estudo da Matemática pois, às vezes, aprendem o conteúdo de forma mecânica, ou seja, costumam apenas memorizar o conteúdo sem a devida compreensão do tema que está sendo lecionado. Neste tipo de aprendizagem, uma nova informação não é relacionada a conceitos já existentes na estrutura cognitiva ou, quando não existem tais conceitos, a nova informação não é relacionada de forma significativa. Desta forma, o aprendiz acaba incorporando novos conteúdos sem que estes se vinculem a conceitos especificamente relevantes preexistentes em sua estrutura cognitiva. 
Os discentes ao acreditarem que o processo de ensino aprendizagem se dá por meio da memorização de conteúdos, criam o conceito de que aprender tal disciplina é a aplicação de regras que foram ensinadas pelo professor, não relacionando o conteúdo com o seu cotidiano.

Diante deste cenário escolar, os educadores necessitam cada vez mais de opções pedagógicas que os auxiliem no processo de aprendizagem. As tecnologias podem ser recursos altamente eficientes para a melhoria deste processo. Partindo deste contexto, acredita-se que a inserção das TIC's na educação necessita ser mais explorada, mostrando suas possibilidades e avanços, para que professores e demais pesquisadores possam sentir a necessidade da aliança entre educação e tecnologias que favoreçam o processo de ensino-aprendizagem.

Dessa forma, este trabalho teve como objetivo verificar a eficácia dos OA's (Objetos de Aprendizagem) que foram desenvolvidos para avaliar o processo de ensino e aprendizagem dos alunos do $8^{\circ}$ ano do Ensino Fundamental II, em relação aos conceitos de números racionais.

\section{Referencial Teórico}

A fundamentação teórica desta pesquisa consiste na Teoria da Aprendizagem Significativa de Ausubel. Segundo Silva (2014), o conceito central que Ausubel se baseia para descrever sua teoria é o de aprendizagem significativa, que segundo ele é "[...] um processo através do qual uma nova informação se relaciona com um aspecto relevante já existente na estrutura cognitiva do indivíduo". Este processo envolve a interação de uma nova informação com uma informação já existente na estrutura de conhecimento do indivíduo (AUSUBEL et al., 1980, p. 56).

Ausubel diz que "[...] a aprendizagem significativa é o mecanismo humano, por excelência, para adquirir e armazenar a vasta quantidade de ideias e informações representadas em qualquer campo de conhecimento" (AUSUBEL et al., 1980, p. 56). Ou seja, para que ocorra a aprendizagem significativa, o ensino aprendizagem deve se desenvolver a partir da assimilação dos conhecimentos prévios dos estudantes (SILVA, 2014).

Durante a aprendizagem significativa, para Ausubel, os conhecimentos novos dos alunos relacionam-se com os conhecimentos prévios que estes já possuem. Quando isso ocorre, os discentes conseguem expressar este novo conhecimento em sua própria linguagem. Ausubel define estes conhecimentos prévios como subsunções.

Quando não ocorre a aprendizagem significativa, ocorre então a aprendizagem mecânica, em que os novos conhecimentos adquiridos pelos alunos estão "soltos", ou seja, eles não relacionam a ideias relevantes disponíveis em sua estrutura cognitiva. Dessa forma, os discentes não conseguem expressar tais conhecimentos com suas próprias palavras, apenas repetindo e memorizando as palavras do professor. Nesse caso, na aprendizagem mecânica, ao contrário da aprendizagem significativa, as informações são aprendidas praticamente sem interagir com informações relevantes presentes na estrutura cognitiva, de tal forma que a nova informação é armazenada de maneira arbitrária e literal. Vale dizer que: 
A natureza e condições da aprendizagem receptiva significativa exigem um tipo de aula expositiva que leve em consideração os princípios da diferenciação progressiva e integração que caracterizam a aprendizagem, a retenção e a organização do conteúdo acadêmico na estrutura cognitiva do aluno. O primeiro princípio afirma que grande parte da aprendizagem e toda a retenção e organização dos assuntos são fundamentalmente hierárquicos, procedendo de cima para baixo em termos de nível de abstração, generalização e abrangência. A integração entre os assuntos é facilitada nas aulas expositivas se o professor e/ou os recursos didáticos disponíveis anteciparem explicitamente o emaranhado de semelhanças e diferenças entre as novas ideias relevantes e as preexistentes na estrutura cognitiva de cada aluno. (AUSUBEL et al., 1980, p. 97).

Pode ocorrer do aluno não possuir os subsunçores, então Ausubel sugere o uso de organizadores prévios. Estes são instrumentos que permitem a integração dos novos conceitos. Segundo ele, a principal função do organizador prévio é ser uma "ponte cognitiva" entre o que o estudante sabe e o que ele deve saber. Segundo Tavares (2004 apud NUNES, 2011), as "animações" interativas podem configurar-se como organizadores prévios facilitadores da construção de significados.

Assim, o material deve ser elaborado de forma que proporcione ao aluno a possibilidade de realizar as relações entre sua estrutura cognitiva preexistente e os novos conceitos que estão sendo abordados no material de uma maneira hierárquica. Sendo assim, se alguma destas condições não for satisfeita o processo de aprendizagem significativa poderá não ocorrer.

\subsection{Objetos de Aprendizagem}

De um modo geral, os objetos de aprendizagem (OA)'s são softwares educacionais. Para Audino (2012), objetos de aprendizagem "são recursos digitais dinâmicos desenvolvidos com fins educacionais. Eles cobrem diversas modalidades de ensino: presencial ou distância; diversos campos de atuação: educação formal, corporativa ou informal, entre outras".

O OA pode ser utilizado em diversos contextos e ambientes virtuais, auxiliando os alunos na aprendizagem e promovendo a criatividade por meio da utilização de diversas mídias. Além disso, é uma estratégia que pode facilitar o relacionamento do conhecimento cotidiano dos alunos com os conteúdos ministrados em sala de aula.

Entretanto, vale dizer que OA por si só não poderá suprir todas as necessidades do ensino. É necessária a presença de um professor em função da utilização de novos métodos para que todas as vantagens de utilização do OA sejam verdadeiramente exploradas, de tal forma que professores e alunos sejam envolvidos no processo de ensino e aprendizagem.

\section{Metodologia}

A criação dos OA's desenvolvidos para realização deste trabalho foram produzidos utilizando o software Adobe Flash CS5. Este software foi primariamente originado de gráfico vetorial. Apesar de suportar imagens bitmap e vídeos, é utilizado geralmente para a criação de animações 
interativas que funcionam embutidas num navegador web e por meio de desktops, celulares, smartphones, tablets e televisores (veja Figura 1).

Figura 1 - Tela inicial do software.

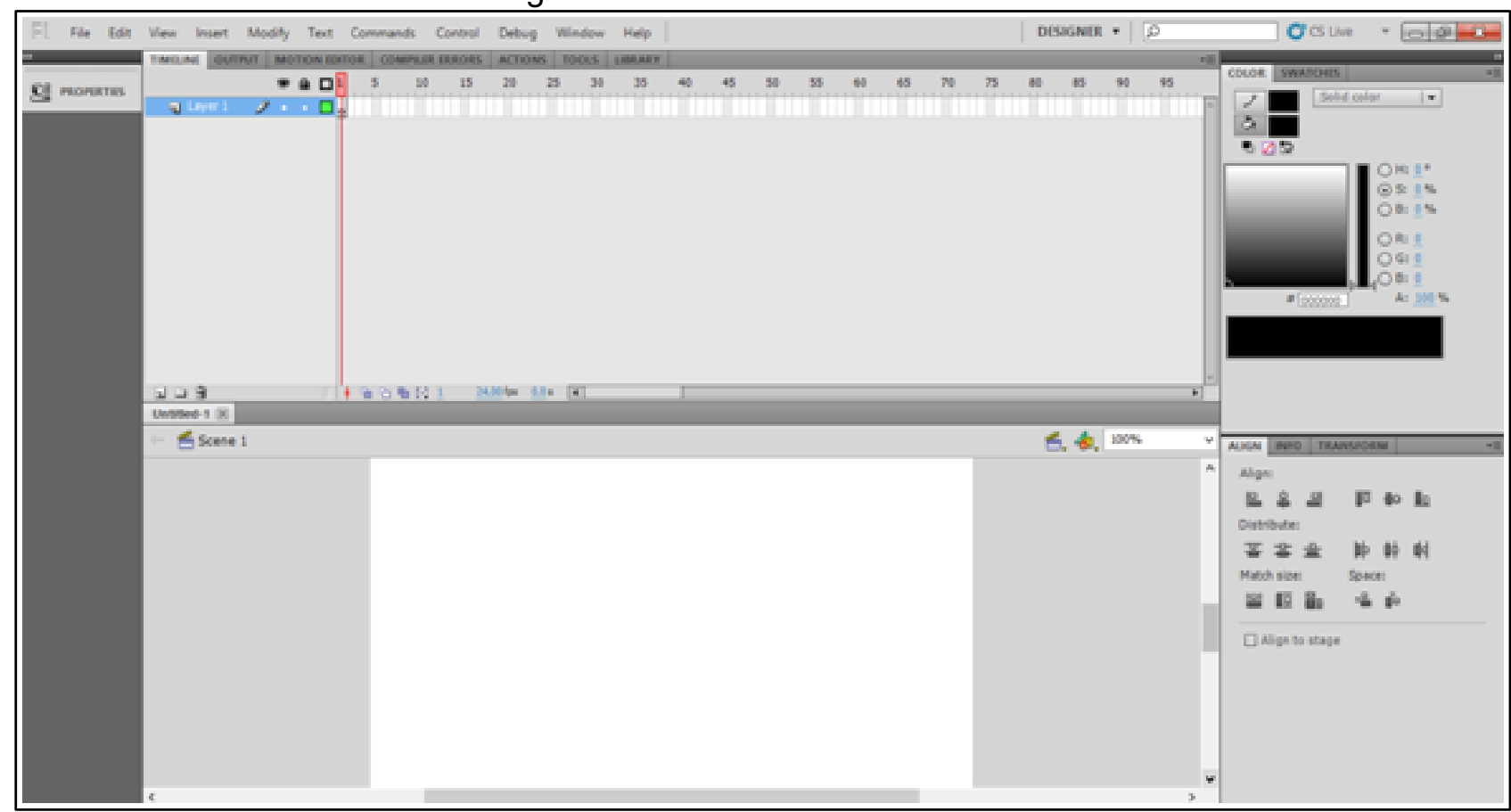

Fonte: Elaboração dos autores.

Tais OA's foram aplicados em uma turma de 32 alunos do $8^{\circ}$ ano do Ensino Fundamental de uma escola pública do Estado de Minas Gerais, em Rio Pomba. Os alunos participantes deste trabalho tinham a faixa etária compreendida entre 13 e 16 anos de idade.

Os OA's são jogos nos quais, à medida em que o aluno vai acertando as questões, os pontos são acumulados e quando termina o jogo, é mostrada a soma da pontuação. O primeiro jogo retrata os números racionais na forma fracionários e as suas operações, enfatizando principalmente a adição e subtração de frações com denominadores diferentes, bem como operações de multiplicação e divisão de números racionais da forma fracionários. O segundo OA, é semelhante ao show do milhão ${ }^{1}$, em que cada questão possui uma determinada pontuação que varia com nível de dificuldade de cada uma delas.

Para a produção dos Objetos de Aprendizagem, primeiramente foi feito um levantamento em sala de aula com os alunos a fim de analisar suas dificuldades referentes ao conteúdo de números racionais. Muitos discentes afirmaram que não conseguiam realizar as operações de números decimais, mesmo aqueles que já tivessem estudado esse conteúdo em anos anteriores. Diante disto foi elaborado um pré-teste com o intuito de verificar os conhecimentos prévios dos

\footnotetext{
${ }^{1}$ Foi um programa de televisão brasileiro de perguntas e respostas, que concedia um prêmio máximo de um milhão de reais. Fonte: <http://www.sbt.com.br/sbtnaweb/midias/84019/SBT-lanca-aplicativo-do-Show-doMilhao.html>. Acesso em: 8 maio 2018.
} 
alunos a respeito dos números racionais. Ao avaliar o pré-teste, pôde-se constatar que mais da metade dos alunos da turma não souberam realizar as operações aritméticas envolvendo números racionais tendo em vista os erros encontrados depois da correção do referido pré-teste.

Após análise do resultado do pré-teste, foi elaborado o primeiro material para realização deste trabalho. Este $\mathrm{OA}$ consistia em questões que abordavam operações aritméticas relacionadas aos números fracionários. A maioria dos discentes não sabia calcular soma e subtração de frações com denominadores diferentes e nem dividir frações. Assim, este OA teve por objetivo mostrar a diferença entre as operações de adição e subtração de números racionais com denominadores iguais e diferentes como mostra a Figura 2.

Figura 2 - Telas do OA. (A): Tela do inicial do OA; (B): Tela do primeiro material.

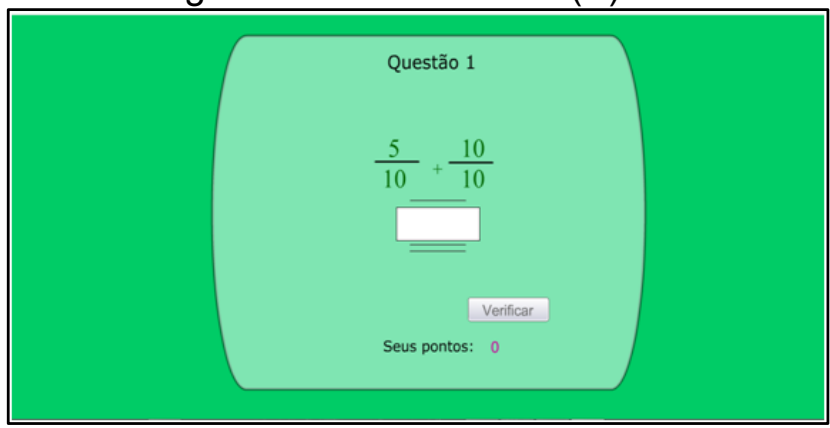

(A)

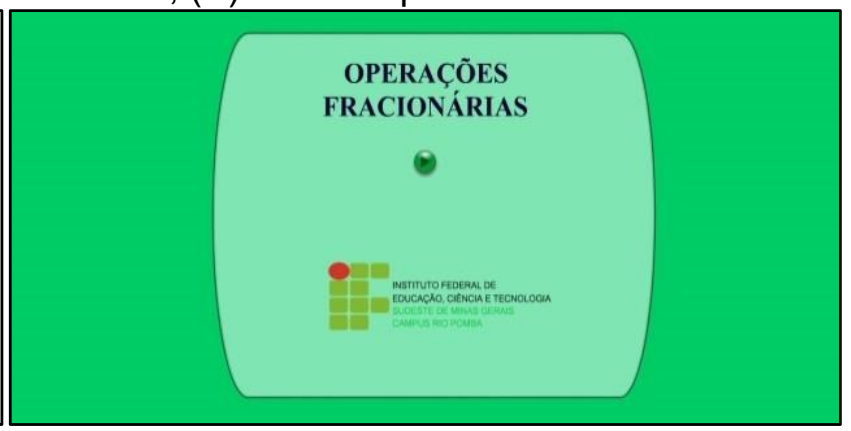

(B)

Fonte: Elaboração dos autores.

O intuito maior desse OA foi buscar a compreensão e motivação dos alunos em relação às operações envolvendo números fracionários. Pôde-se constatar que a maioria dos alunos não sabiam calcular o Mínimo Múltiplo Comum (M.M.C) e acreditavam que para somar ou subtrair números fracionários, somava-se o numerador com o numerador, e o denominador com o denominador. Observe na Figura 3 alguns alunos realizando a primeira atividade.

Figura 3 - Alunos realizando a primeira atividade.

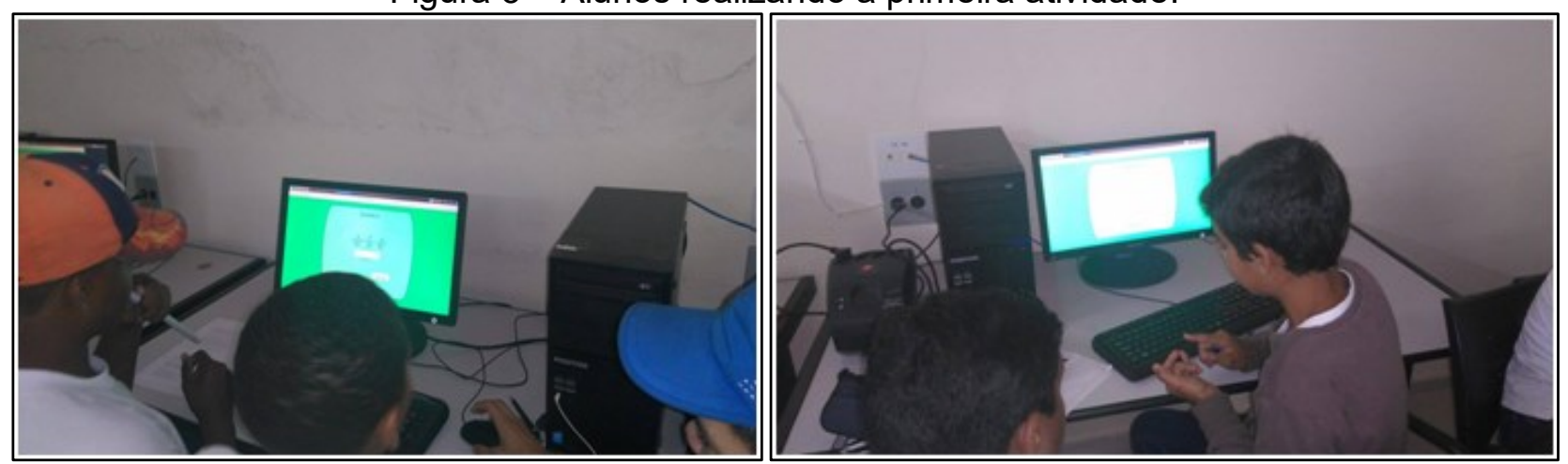

Fonte: Imagens da pesquisa.

O segundo OA consistia nas operações dos números decimais e também foi confeccionado em forma de jogo com o propósito de atrair a atenção dos alunos. Veja a Figura 4 que retrata o segundo objeto de aprendizagem. 
Figura 4 - Telas do segundo OA. (A): Tela do segundo material; (B): Tela inicial do jogo.

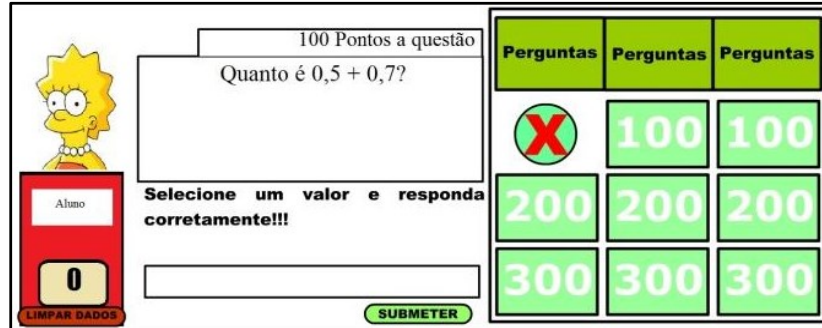

(A)

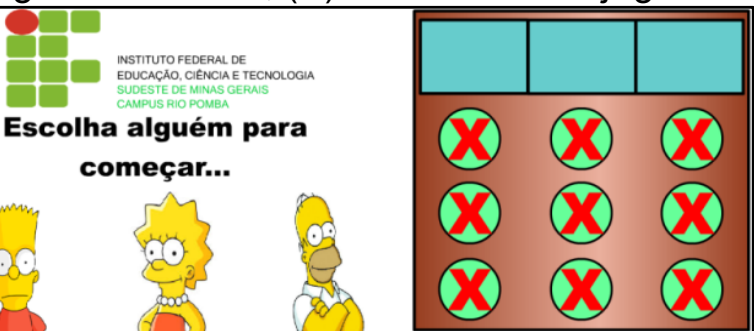

(B)

Fonte: Elaboração dos autores.

Nesta atividade os alunos apresentaram maior dificuldade, pois resistiram em realizar as operações aritméticas de forma manual ao dizerem que preferiam utilizar a calculadora para realizar tais operações. Entende-se que tal instrumento promove uma repetição de procedimentos, o que na maioria das vezes poderia inibir o raciocínio.

Provavelmente, os alunos que encontraram dificuldade em realizar operações com números decimais, se deve ao fato do hábito frequente em realizar as operações aritméticas por meio do uso da calculadora. Assim, como estratégia de ensino e aprendizagem das operações com números decimais, não foi permitido nessa atividade, o uso das calculadoras para que os alunos pudessem compreender o significado das operações, de forma substantiva e não arbitrária. Veja na Figura 5 os alunos realizando a segunda atividade.

Figura 5 - Alunos realizando a segunda atividade.

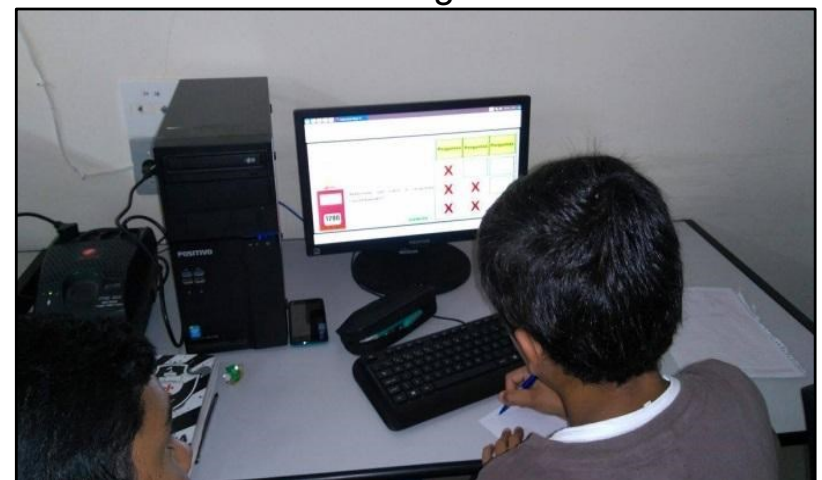

(A)

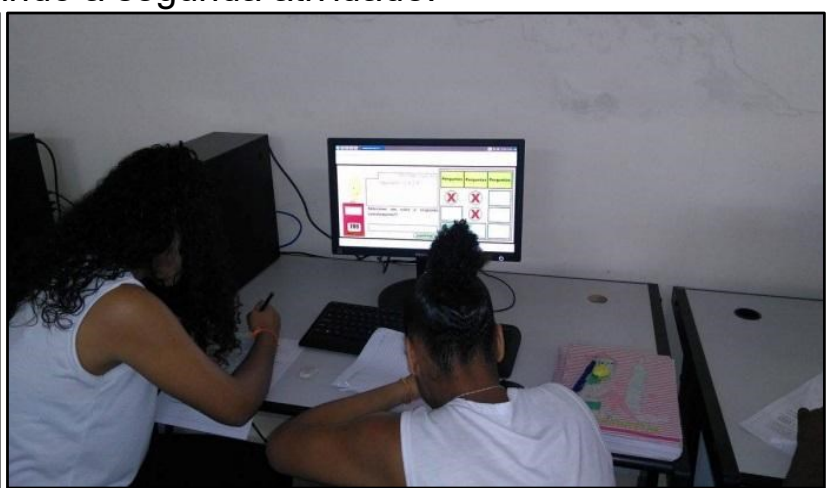

(B)

Fonte: Imagens da pesquisa.

Ao final das duas atividades, foi aplicado um pós-teste e um questionário a respeito das opiniões dos alunos com relação aos materiais aplicados.

\section{Resultados e Discussão}

O primeiro teste, composto por cinco questões, foi respondido pelos 32 alunos da turma. $\mathrm{O}$ resultado da correção é mostrado na Figura 6. 
Figura 6 - Gráfico a respeito das notas do pré-teste.

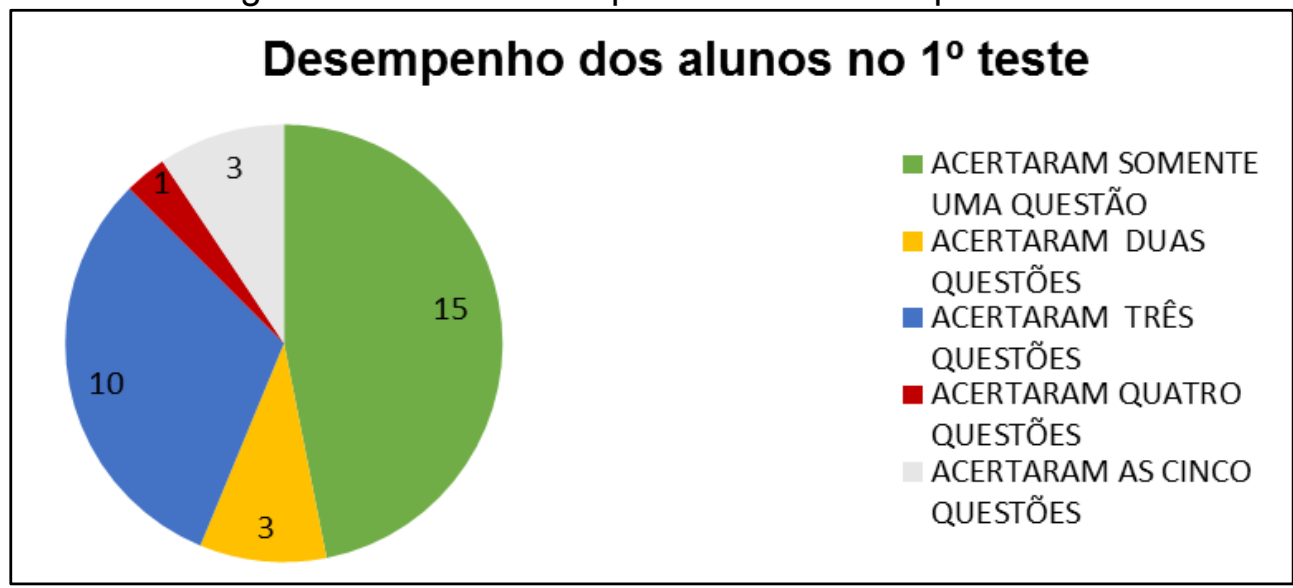

Fonte: Dados da pesquisa.

De acordo com análise da Figura 6, pôde-se constatar que 46,8\% dos alunos acertaram uma questão; 9,3\% acertaram duas questões; $31,2 \%$ acertaram três questões; $3,1 \%$ acertaram quatro questões e 9,3\% acertaram cinco questões.

Ao aplicar o primeiro teste e observar o comportamento e os questionamentos dos alunos, pôde-se perceber que a maioria deles não possuíam os conhecimentos prévios adequados para que ocorresse uma aprendizagem significativa. Como já foi dito, a maioria dos alunos não sabiam realizar as operações aritméticas, o que pode dificultar a ocorrência da aprendizagem significativa.

Analisando o segundo teste, conforme Figura 7, pode- se observar que $12,5 \%$ dos alunos acertaram uma questão; $6,2 \%$ acertaram duas questões; $40,6 \%$ acertaram três questões; $21,8 \%$ acertaram quatro questões e $18,7 \%$ acertaram as cinco questões.

Figura 7 - Gráfico a respeito das notas do pós-teste.

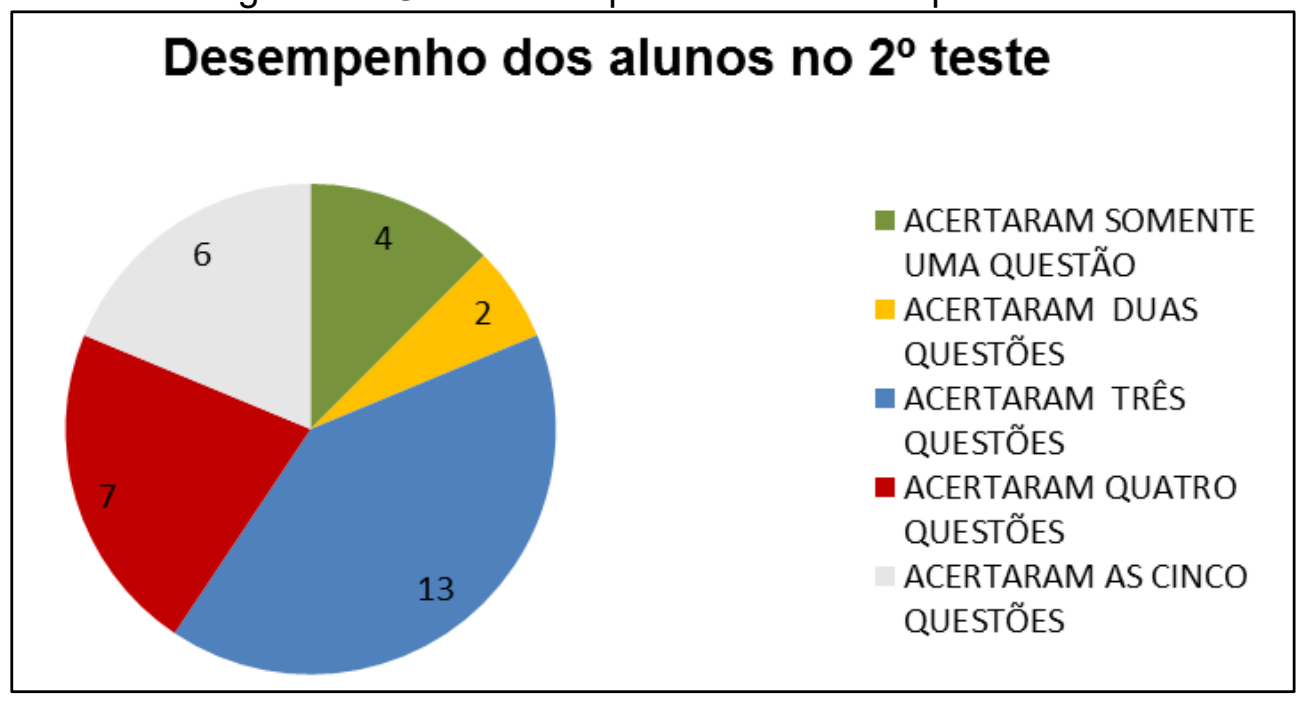

Fonte: Dados da pesqusia.

Comparando os dois gráficos referentes ao pré-teste e o pós-teste, verificamos que o desempenho dos alunos melhora depois da aplicação da atividade utilizando o OA. Vale esclarecer que o nível de dificuldade dos dois testes foi similar. 
Após aplicação das atividades, ao final da aula, foi entregue um questionário aos alunos para saber as suas opiniões a respeito dos objetos de aprendizagem.

As figuras de números 8 a 12 retratam as opiniões dos alunos acerca do questionário sobre os OA's.

Figura 8 - Gráfico da primeira questão do questionário.

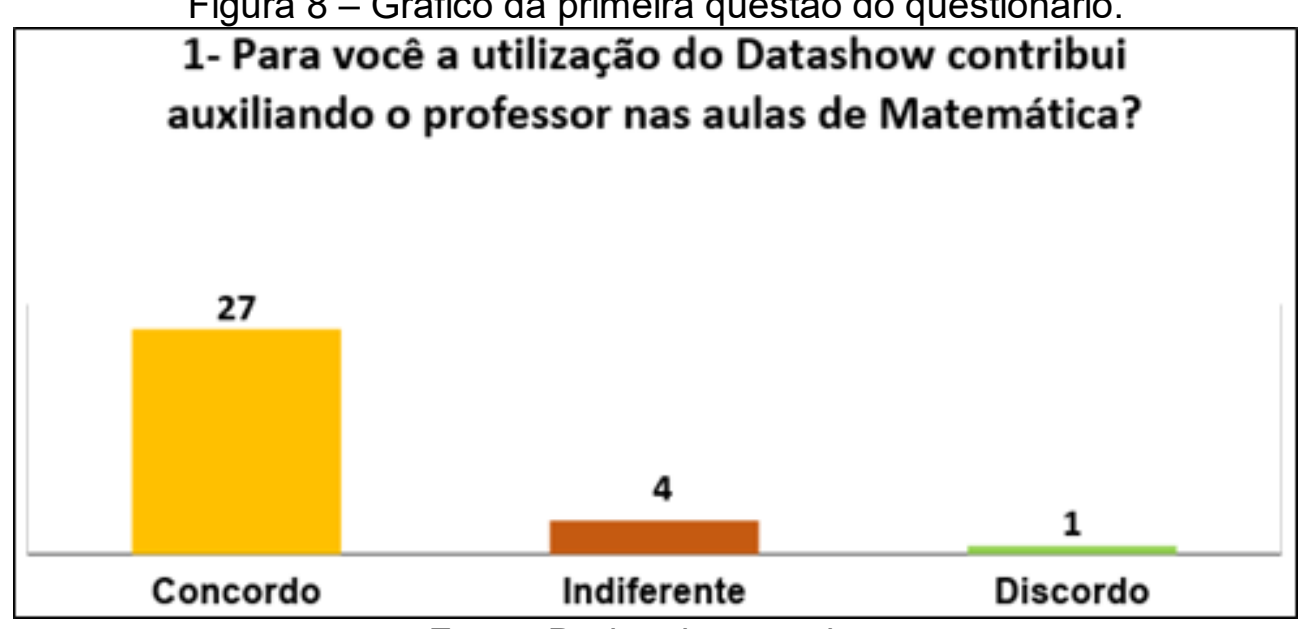

Fonte: Dados da pesquisa.

De acordo com a Figura 8, pode-se perceber que a maioria dos alunos concordaram que o Datashow pode auxiliar o professor. Neste aspecto percebe-se que os efeitos visuais podem ter favorecido um resultado positivo para este trabalho.

Figura 9 - Gráfico da segunda questão do questionário.

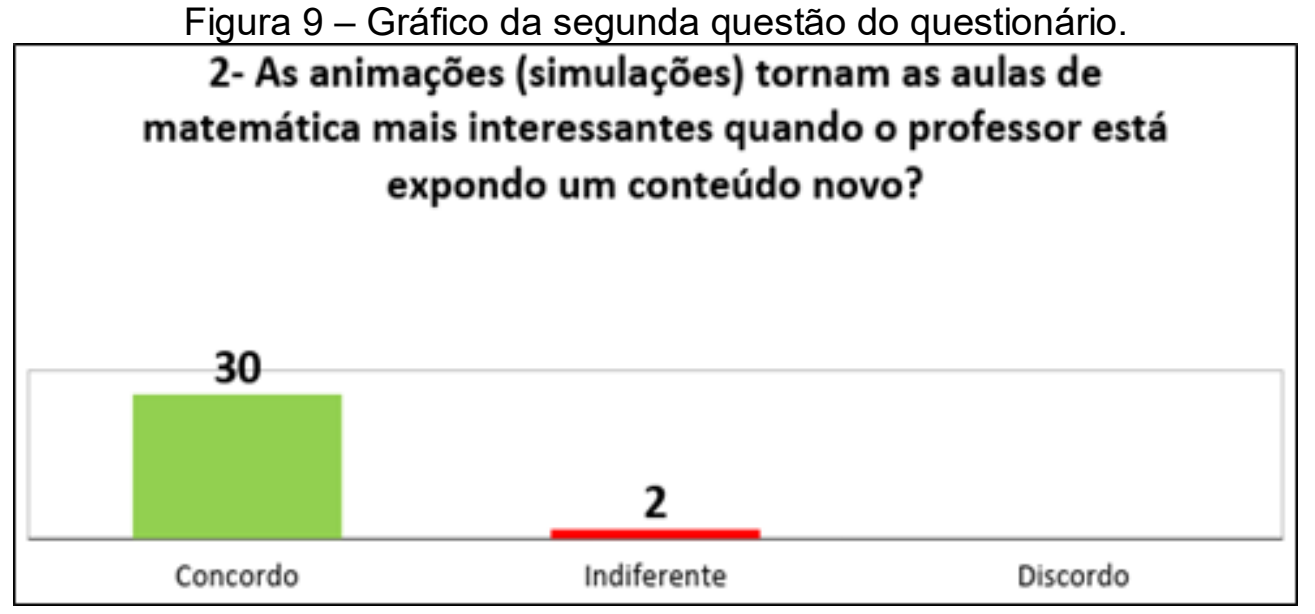

Fonte: Dados da pesquisa.

De acordo com a Figura 9, pode-se constatar que a maioria dos alunos afirmaram que o professor ao introduzir na aula algo diferente, como por exemplo, as animações, elas ficam mais interessantes. Isto indica que o uso desta estratégia motivou os discentes para aprendizagem do conteúdo proposto, apesar de dois alunos manifestarem indiferença ao método utilizado. 
Figura 10 - Gráfico da terceira questão do questionário.

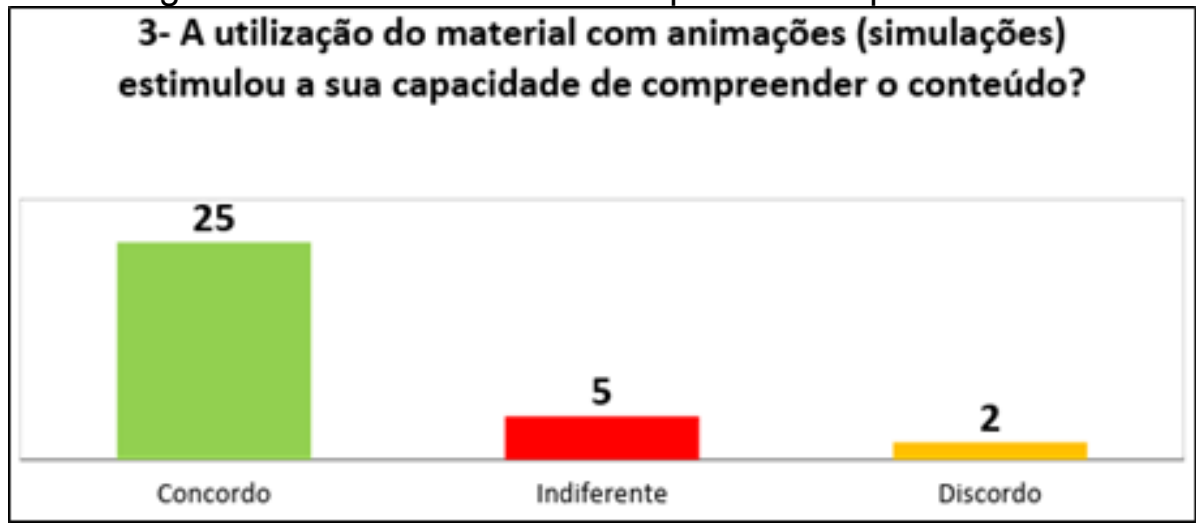

Fonte: Dados da pesquisa.

A Figura 10 mostra o resultado da terceira questão, em que a maioria dos alunos afirmaram que o uso de animações estimulou a capacidade deles de compreenderem o conteúdo de números racionais. Entretanto, $21,8 \%$ dos alunos foram indiferentes ou discordam da utilização dos OA's durante as aulas de matemática em que foi aplicada a referida atividade.

Figura 11 - Gráfico da quarta questão do questionário.

4- A forma como o assunto foi abordado com a utilização do software contribuiu para a sua aprendizagem?

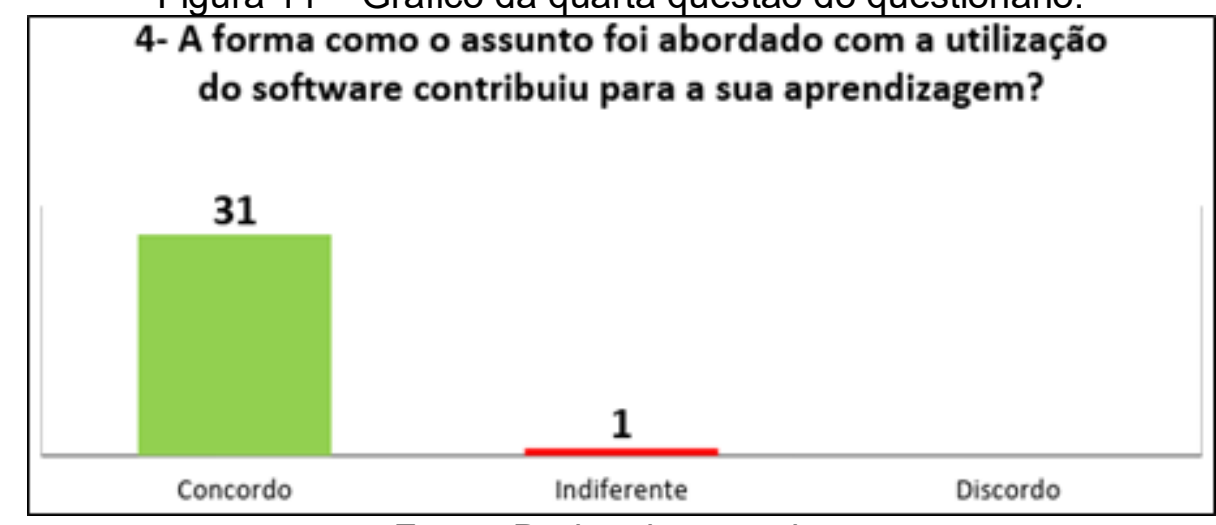

Fonte: Dados da pesquisa.

Em relação à quarta pergunta, pode-se verificar conforme Figura 11, com exceção de um estudante, todos os alunos da turma afirmaram que o OA contribuiu positivamente para a aprendizagem do conteúdo estudado.

Figura 12 - Gráfico da sexta questão do questionário.

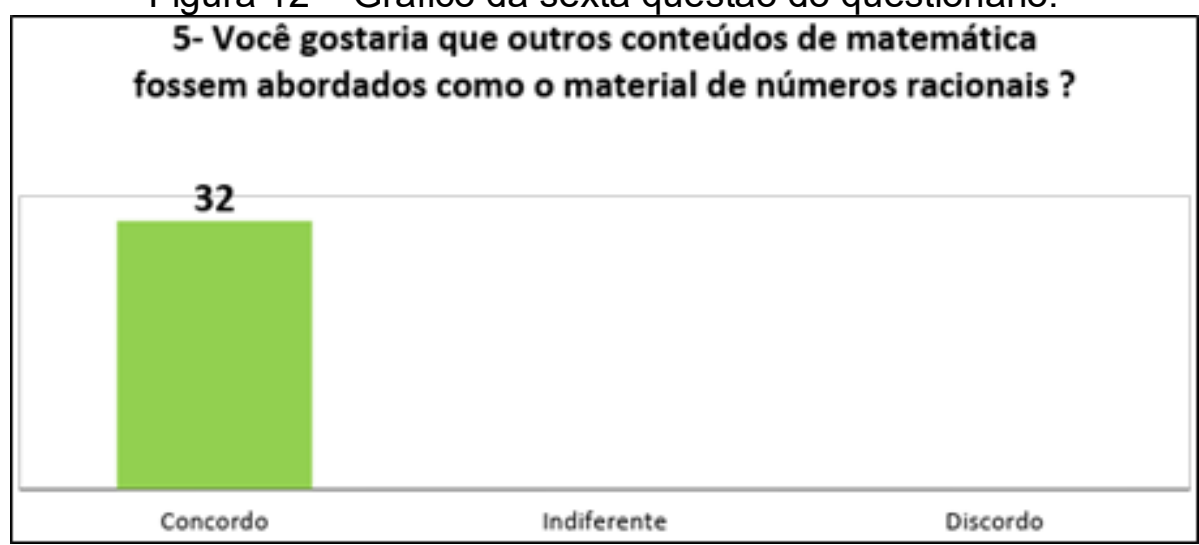

Fonte: Dados da pesquisa. 
Na última questão, como mostra a Figura 12, pode-se constatar que os alunos da turma foram unânimes em afirmar que seria interessante utilizar OA's para ensinar outros conteúdos de Matemática.

Pelo exposto, vale dizer que SILVA et al. (2008), argumentam que, quando a criança está "brincando", acaba por apreender a estrutura lógica do material que, por consequência, é levada a apreender também os conceitos matemáticos presentes nesse OA. Tal argumento se aplica também a faixa etária entre 13 e 16 anos do grupo de alunos em estudo considerando que eles estão com uma idade num processo de transição entre serem crianças e/ou adolescentes. Por isso destaca-se a importância dos jogos via computador que têm um aspecto lúdico, mas adquirem o caráter de material de ensino e aprendizagem. Entretanto, vale ter o cuidado de não dar conotação aos jogos com propósito apenas lúdico ou mero passatempo, pois tal possibilidade pode desviar a atenção dos alunos do processo de ensino e aprendizagem.

Por meio da análise quantitativa dos gráficos acerca do comparativo das notas do pré-teste com o pós-teste ficou evidenciado que houve maior número de acertos no pós-teste em relação ao pré-teste. Isto é um indicativo de que os alunos em estudo melhoram o rendimento escolar, o que pode ser atribuído na utilização dos OA's como estratégia de ensino com êxito. Além disso, pôdese perceber também que a utilização dos OA's nas aulas de matemática houve uma grande interação entre os discentes no processo de ensino e aprendizagem.

A análise do resultado dos questionários demonstrou que os alunos em estudo foram motivados para realizar as atividades utilizando o computador, o que pode ter favorecido o desenvolvimento destes de forma positiva a maneira correta de realizar operações aritméticas com os números racionais.

\section{Considerações Finais}

De acordo com este trabalho, foi possível verificar que os objetos construídos tiveram boa recepção para o ponto de vista dos estudantes em estudo. Além disso, pôde-se observar que a utilização do software favoreceu a participação e interação da grande maioria dos alunos ao utilizar os OA's no decorrer das aulas ministradas para este estudo, o que evitou conversas paralelas não condizentes com o conteúdo ministrado.

Além do objetivo de analisar os OA's como estratégia de ensino, o presente trabalho também teve o propósito de favorecer uma aprendizagem significativa. Com base nos indicativos das notas atribuídas aos alunos no segundo teste, que foram superiores ao do primeiro teste, pôde-se constatar que a maioria dos alunos em estudo aprenderam as operações aritméticas com os números racionais.

Entretanto, vale dizer que, no âmbito do presente estudo, não obtivemos indicadores precisos para afirmar que, de fato, houve ou não a ocorrência de uma aprendizagem significativa na perspectiva de Ausubel. Mas, vale esclarecer que este estudo não pretendeu esgotar o tema, 
mas principalmente anunciar a importância de se considerar à possibilidade de utilizar os OA's como estratégia de ensino e conceber a aprendizagem significativa no contexto educativo.

Embora, os resultados obtidos sejam positivos ao analisarmos os OA's como estratégia de ensino, vale ressaltar que, de acordo com as observações realizadas no decorrer deste trabalho, o quanto é importante e necessária à participação do professor como mediador no processo de ensino e aprendizagem. Pois, de acordo com nossas observações, percebemos uma tendência dos alunos em estudo, a prática da memorização e utilização de calculadoras de forma arbitrária, o que pode causar certa dificuldade quanto ao entendimento dos conteúdos ministrados. Por isso, consideramos importante a participação do professor, bem como ele estimular a aprendizagem significativa na aplicação das tarefas didáticas à luz da Teoria da Aprendizagem Significativa de Ausubel a fim de se evitar uma aprendizagem de conteúdos sem sentido para os aprendizes.

Por último, apesar da nossa experiência com este trabalho ter mostrado que não seja fácil mudar a tradição do processo de ensino-aprendizagem de matemática, há indicações de que é possível explorar estratégias com êxito de modo a despertar nos estudantes, maior interesse por esta disciplina de grande importância para a formação intelectual.

\section{Referências}

AUDINO, D. F. Objetos de aprendizagem hipermídia aplicao à cartografia escolar no sexto ano do Ensino Fundamental em Geografia. 2012. 153 f. Dissertação (Mestrado em Geografia) Programa de Pós-Graduação em Geografia. Universidade Federal de Santa Catarina, 2012.

AUSUBEL, D. P.; NOVAK, J. D.; HANESIAN, H. Psicologia Educacional. Rio de Janeiro: Interamenicana, 1980.

BRASIL. Secretaria de Educação Fundamental. Parâmetros curriculares nacionais: introdução aos parâmetros curriculares nacionais. Brasília: MEC/SEE, 1998.

NUNES, Eliana dos Reis. Ensino de Conceitos Físicos no Ensino Médio e as contribuições dos objetos de aprendizagem. 2011. Tese (Doutorado em Educação) - Faculdade de Educação. Universidade de São Paulo, 2011.

PONTE, J. P., OLIVEIRA, H.; VARANDAS, J. M. O contributo das tecnologias de informação e comunicação para o desenvolvimento do conhecimento e da identidade profissional. In: Fiorentini, D. (Ed.). Formação de professores de Matemática: Explorando novos caminhos com outros olhares. Campinas: Mercado de Letras, 2003. p. 159-192.

SANTOS, J. J. A.; MOITA, F. M. G. S. C. Objetos de Aprendizagem e o Ensino de Matemática Análise de sua importância na aprendizagem de conceitos de probabilidade. 2016. Disponível em: <http://www.pucrs.br/famat/viali/tic literatura/artigos/objetos/comunica13.pdf>. Acesso em: 20 maio 2017.

SILVA, Alexandre da. Objetos de aprendizagem: Uma alternativa para o ensino de conceitos de eletrostática no Ensino Médio. 2014. 213 f. Dissertação (Mestrado em Ensino de Ciências Naturais) - Programa de Pós-Graduação em Ensino de Ciências Naturais, Universidade Federal do Mato Grosso, Cuiabá, MT, 2014. Disponível em: <http://ri.ufmt.br/handle/1/383>. Acesso em: 6 maio 2018. 
SILVA, E. M.; MOITA, F. M. G. S. C.; SOUSA, R. P. Jogos Eletrônicos: construindo novas trilhas. Campina Grande: EDUEP, 2008.

SMOLE, K. C. S.; DINIZ, M. I. S. V. Matemática Ensino Médio: Manual do professor com orientações didáticas. 5. ed. São Paulo: Saraiva, 2005. 